\title{
Kriteria Pemilihan Pemasok Menggunakan Analytical Network Process
}

\author{
Dewi Kurniawati ${ }^{*}$, Henry Yuliando ${ }^{1}$, Kuncoro Harto Widodo ${ }^{1}$
}

\begin{abstract}
The selection of supplier is a strategic decision in supply chain which increase competitive advantages. Every manufacture needs to have a standard supplier selection that appropriate with the requirement of the company. The aims of this paper are promoting some criterias of supplier selection and testing whether there are differences interests against priority criteria referred to of strata tenure distinct. Weights and priorities of the criteria tested with a method of analytic network process (ANP) are also intended to bring up a relation of mutual influence among the criteria. ANP can be used to help making decision of selection supplier and to manage supply chain performance. This paper shows the criteria that influence are the past perfomance, price, communication systems, and a supplier of professionalism is the priority for the production of the company. In the other hand, the importance of management is the delivery time, consistent quality, price, and number of delivery. The difference in perspective is influenced by the level of interest and different responsibilities. The difference this assessment formed the basis of decision-making and strategic policies of the supply chain according to the condition of the company.
\end{abstract}

Keywords: Criteria, supplier, Analytical Network Process (ANP).

\section{Pendahuluan}

Salah satu faktor kesuksesan sebuah perusahaan adalah pemilihan pemasok (Gencer and Gurpinar [8]). Pemilihan pemasok yang tepat dapat menjamin ketersediaan bahan baku untuk menjaga lintasan produksi. Menurut Ghoddsypour and O'Brien [9] pemilihan pemasok merupakan masalah pengambilan keputusan penting agar mendapatkan pemasok yang dapat meningkatkan daya saing perusahaan. Dapat dikatakan pemilihan pemasok adalah salah satu aktivitas penting pada bagian pengadaan untuk mencapai keunggulan bersaing (Amid et al. [1]).

Pemilihan pemasok adalah permasalahan multi kriteria dimana setiap kriteria yang digunakan mempunyai kepentingan yang berbeda dan informasi mengenai hal tersebut tidak diketahui secara tepat. Dalam hal ini pemilihan pemasok yang berdasarkan penawaran harga yang rendah sudah tidak efisien lagi. Untuk mendapatkan kinerja rantai pasok yang maksimal harus menggabungkan kriteria lain yang relevan dengan tujuan perusahaan ( $\mathrm{Ng}$ [14]).

Analisis keputusan pemilihan pemasok harus meliputi strategi dan faktor operasional seperti faktor tangible dan intangible (Cebi and Bayraktar [3]), sedangkan menurut Amid et al [1] pemilihan pemasok

\footnotetext{
$1^{*}$ Fakultas Teknologi Pertanian, Jurusan Teknologi Industri Pertanian, Universitas Gadjah Mada, Jl. Flora, Bulaksumur Yogyakarta 55281 Indonesia. Email: dewi_tip08@yahoo.com

* Penulis korespondensi
}

yang bersifat multi kriteria harus meliputi faktor kualitas dan kuantitas. Pada umumnya terdapat beberapa kriteria yang mempengaruhi dalam pemilihan pemasok, misalnya dalam hal kualitas meliputi pengiriman, kinerja masa lalu, garansi, harga, kemampuan teknik, dan kondisi finansial (Hapsari dan Suparno [10]). Menurut Yoserizal dan Singgih [19] pemilihan pemasok yang tepat tidak hanya pemasok yang dapat memberikan material yang berkualitas, tepat waktu, dan harga terjangkau namun juga harus memberikan service yang optimal baik dari segi responsif, kelancaran komunikasi dan informasi. Lin [13] mengembangkan kriteria harga, kualitas, service, ketepatan pengiriman, dan kepercayaan sebagai dasar pemilihan pemasok. Amid et al. [1] menerapkan kriteria biaya, kualitas, dan service.

Pemilihan pemasok adalah masalah pengambilan keputusan yang melibatkan multi-person. Input diperoleh dari pendapat para ahli yang mempunyai cara pandang, tanggung jawab, pengalaman sebagai pengambil keputusan. Penilaian kriteria diputuskan oleh bagian manajemen dan bagian produksi berdasarkan strategi rantai pasoknya (Amid et al. [1]). Proses pengambilan keputusan dapat diterjemahkan dengan pendekatan sistematis dan logika untuk mendapatkan prioritas dan bobot (Tam and Tumala [16]).

Lunar Cipta Kreasi merupakan perusahaan yang bergerak di bidang kerajinan. Lunar Cipta Kreasi memperoleh bahan baku dari beberapa pemasok untuk mengantisipasi pemesanan berlebih. 
Pemilihan pemasok di Lunar Cipta Kreasi hanya didasarkan oleh spesifikasi material. Dalam produksinya Lunar Cipta Kreasi mendasarkan pada pesanan dengan jangka waktu yang ditetapkan di dalam kontrak. Dalam hal ini Lunar Cipta Kreasi akan memilih pemasok yang mampu memberikan spesifikasi material yang diinginkan dengan harga yang kompetitif untuk memenuhi pesanan. Dalam prakteknya sering bahan baku diperoleh dari beberapa pemasok tergantung pada kuantitas dan kualitas yang dibutuhkan. Namun seiring dengan persaingan yang semakin ketat, perusahaan dituntut tidak hanya mempertimbangan harga namun juga kriteria lain seperti kualitas, service dan lainlain.

Penelitian ini ditujukan untuk memunculkan sejumlah kriteria dalam pemilihan pemasok dengan mengambil studi di perusahaan kerajinan Lunar Cipta Kreasi, Yogyakarta. Pengambilan keputusan pemilihan pemasok yang saat ini dijalankan perusahaan masih bersifat intuitif sehingga tidak dapat terdapat konsistensi dalam kriteria pemilihan pemasok yang digunakan.

Berbagai metode dapat digunakan dalam permasalahan pemilihan pemasok yang melibatkan banyak kriteria. Ng Wang L [14] melakukan pembobotan multi kriteria dalam pemilihan pemasok menggunakan metode data envelopment analysis (DEA). Lin [13] menggunakan analytic network process (ANP) dan similarity to ideal solution (TOPSIS) untuk menghasilkan bobot dan rangking pemasok sedangkan program linear digunakan untuk mengalokasikan permintaan setiap pemasok. Chen [5] mengembangkan strategi kompetitif dalam rantai pasok dengan menggunakan analisis SWOT untuk mendapatkan kerangka kriteria dan indikator pemilihan pemasok. Dewayana dan Budi [7] menyatakan jika kriteria yang akan digunakan untuk mengevaluasi pemasok mempunyai hubungan keterkaitan maka metode yang tepat digunakan adalah ANP, namun jika kriteria tersebut tidak mempunyai hubungan keterkaitan maka metode yang tepat untuk digunakan adalah Analytical Hierarchy Porcess (AHP)

Hasil observasi memberikan informasi bahwa Lunar Cipta Kreasi perlu menata ulang sistem evaluasi pemilihan pemasok. Kriteria yang digunakan harus disesuaikan dengan kebutuhan, obyektifitas dan keberadaan sumber daya perusahaan. Kriteria yang digunakan Lunar Cipta Kreasi mempunyai hubungan keterkaitan satu sama lain maka metode yang tepat untuk digunakan adalah ANP. Selain itu ANP juga dapat digunakan untuk memprediksi bentuk hubungan antar kriteria yang ditinjau.

Menurut Bayazit [2] ANP mampu memperbaiki kelemahan dari AHP dalam hal kemampuan meng- akomodasi keterkaitan antar kriteria pada proses evaluasi pemilihan pemasok. Melalui metode ANP akan diperoleh bobot pada seluruh kriteria yang digunakan dalam pemilihan pemasok (Yoserizal dan Singgih [19]). Hasil dari pembobotan ini dapat digunakan sebagai input dalam menyusun strategi dalam rantai pasok khususnya pemilihan pemasok terutama bagi bahan baku yang relatif kritis yang tentunya membutuhkan hubungan jangka panjang.

Penelitian ini ditujukan untuk memunculkan kriteria yang tepat dalam pemilihan pemasok dan menguji bobot dan prioritas kriteria yang relevan. Selain itu juga penelitian ini didasarkan pada suatu asumsi bahwa cenderung terjadi perbedaan kepentingan antara strata jabatan yang berbeda dalam mempertimbangkan kriteria yang lebih diprioritaskan dalam pemilihan pemasok. Selanjutnya hasil penelitian ini digunakan sebagai dasar pertimbangan atau masukan bagi perusahaan untuk menentukan kebijakan strategis rantai pasok khususnya dalam dalam hal pemilihan pemasok.

\section{Metode Penelitian}

Penelitian ini ditujukan untuk memunculkan sejumlah kriteria dalam pemilihan pemasok dan menguji apakah terdapat perbedaan kepentingan terhadap prioritas kriteria dimaksud dari strata jabatan yang berbeda. Tahap pertama adalah mengidentifikasi kriteria yang digunakan dalam pemilihan pemasok sesuai dengan tujuan perusahaan. Tahap ini dilakukan melalui brainstorming bersifat terbuka sehingga dapat menambahkan kriteria yang dinggap penting bagi Lunar Cipta Kreasi. Kriteria setiap perusahaan akan berbeda dan tergantung pada strategi rantai pasok yang diterapkan (Wang et al. [17]). Celebi [4] dalam penelitiannya menggunakan faktor kualitatif dan kuantitatif yang ditentukan dari literatur dan keahlian manajer perusahaan sebagai pengambil keputusan.

Tahap kedua adalah menentukan hubungan ketergantungan antar kriteria yang dibantu dengan penyebaran kuesioner. Hubungan mempengaruhi antar kriteria digambarkan dengan anak panah (Chung et al. [7]). Interdepensi antar dua kriteria disebut outer dependence yang digambarkan oleh garis dengan dua anak panah sedangkan inner dependence digambarkan dengan loop (Sarkins [28] yang dikutip dari Chung et al. [6]). Dari hubungan ini dapat digunakan untuk membuat model jaringan untuk analisis kriteria dalam pemilihan pemasok.

Tahap ketiga adalah menentukan responden untuk melakukan perbandingan berpasangan antar kriteria yang mempunyai tanggung jawab mengenai keputusan pemilihan pemasok. Penilaian per- 
bandingan berpasangan antar kriteria dibantu dengan penyebaran kuesioner. Menurut (Celebi [4]) perbandingan berpasangan dinilai oleh karyawan dan manajer yang berwenang dalam pengambilan keputusan. Pendapat dari berbagai pihak yang berkepentingan terhadap hubungan dengan pemasok tersebut diuji konsistensinya satu per satu. Selanjutnya dari penilaian responden direkapitulasi dengan rerata geometrik.

Responden yang dimaksud dalam penelitian ini adalah pihak produksi yaitu research and development, quality control, kepala produksi, dan manajer produksi natural bags. Pihak research and development bertugas dalam dalam mendesain model body tas dan memilih pemasok. Pihak quality control melakukan inspeksi body natural bags sebelum dikirim ke perusahaan. Pihak kepala produksi mengawasi jalannya proses produksi natural bags. Pihak manajer produksi natural bags menentukan spesifikasi natural bags dan menyetujui desain dari bagian research and development.

Dalam menguji perbedaan hasil pembobotan kriteria maka dilakukan penilaian kedua yang dilakukan oleh pihak manajemen (direktur operasional) yang mempunyai tanggung jawab terhadap keseluruhan produksi di perusahaan. Hubungan antar para pengambil keputusan dapat ditunjukkan pada bagan struktur organisasi (lihat Gambar 1).

Dalam Analytical Network Process (ANP), responden melakukan perbandingan berpasangan dari elemen yang mempunyai hubungan ketergantungan berdasarkan kriteria kontrolnya. Skala penilaian 1-9, nilai 1 berarti kedua kriteria sama penting sedangkan nilai 9 berarti mendominasi seluruh kriteria (Jharkharia dan Shankar [11]). Perbandingan invers ditunjukkan dengan nilai resiprokal, jika $a_{i j}=1 / a_{i j}$. Hal yang terpenting dalam metode Analytical Network Process (ANP) adalah menghitung bobot prioritas. Bobot prioritas adalah suatu bilangan desimal di bawah satu dengan total prioritas untuk kriteria dalam satu kelompok sama dengan 1. Cara yang paling akurat dalam penghitungan bobot prioritas untuk matriks perbandingan yaitu dengan operasi matematis berdasarkan operasi matriks dan vektor yang dikenal dengan nama eigen vector.

A. $w=\lambda$ maks. $w$

dimana A adalah matriks perbandingan berpasangan, $w$ adalah eigen vektor, $\lambda_{\text {maks }}$ adalah eigen value terbesar dari A (Chung et al. [6]).

Tahap keempat adalah mengolah data kuesioner perbandingan berpasangan. Untuk membantu proses perhitungan digunakan perangkat lunak super decisions. Hasil tahap keempat menghasilkan bobot lokal dan bobot global untuk melihat seberapa besar pengaruh kriteria yang digunakan terhadap pemilihan pemasok.

ANP merupakan metode terbaru dari pengambilan keputusan multi kriteria yang mampu menjelaskan interaksi secara sistematis terutama permasalahan dalam strategi rantai pasok. Selain itu ANP dapat digunakan tidak hanya dalam mengatasi inner dependences dalam kriteria namun juga dapat memberikan jalan untuk memperoleh banyak informasi bagi pengambil keputusan. Jadi metode ini dapat memberikan pandangan bagi perusahaan untuk mengevaluasi dan menentukan pemilihan pemasok yang tepat (Lang [12]).

Penelitian penunjang yang dijadikan dasar penentuan kriteria adalah Dewayana dan Budi [7] menggunakan kriteria harga, potongan harga, ketepatan waktu, reabilitas barang, kualitas barang, kualitas penyerahan barang, cara pembayaran, tenggang waktu pembayaran, komunikasi, dokumentasi, responsif. Hapsari dan Suparno [10] menggunakan kriteria kualitas, waktu pengiriman, jumlah pengiriman, packaging, garansi dan layanan pengaduan, prosedur komplain, responsif, sistem komunikasi, harga, frekuensi pengiriman, kapasitas produksi, pembayaran, struktur organisasi, finansial, dan history. Yoserizal dan Moses [19] menggunakan kriteria kualitas, waktu pengiriman, jumlah pengiriman, packaging, keringanan waktu pembayaran, sistem komunikasi, prosedur complain, responsif,

Tabel 1. Kluster dan kriteria pemilihan pemasok Lunar Cipta Kreasi

\begin{tabular}{ll}
\hline Kluster & Kriteria \\
\hline Biaya $(\mathrm{B})$ & Harga $(\mathrm{H})$ \\
Kualitas $(\mathrm{Ku})$ & Kesesuaian material dengan spesifikasi (SM) \\
& Kemampuan memberikan kualitas yang konsisten (K) \\
Ketepatan $(\mathrm{Ke})$ & Waktu pengiriman (WP) \\
& Jumlah pengiriman (JP) \\
Service $(S)$ & Garansi dan layanan pengaduan (GP) \\
& Responsif (R) \\
Hubungan pemasok $(\mathrm{HP})$ & Sistem komunikasi (SK) \\
& Keprofesionalan pemasok (KP) \\
& Kinerja masa lalu pemasok (KM) \\
& Kekuatan keungan pemasok (KK) \\
\hline
\end{tabular}


garansi dan layanan pengaduan, informasi teknis, harga, diskon, green product, dan green process. Kriteria dari ketiga penelitian tersebut dimodifikasi sesuai dengan keadaan dan tujuan melalui diskusi dengan pihak perusahaan. Kriteria pemilihan pemasok Lunar Cipta Kreasi disajikan pada Tabel 1.

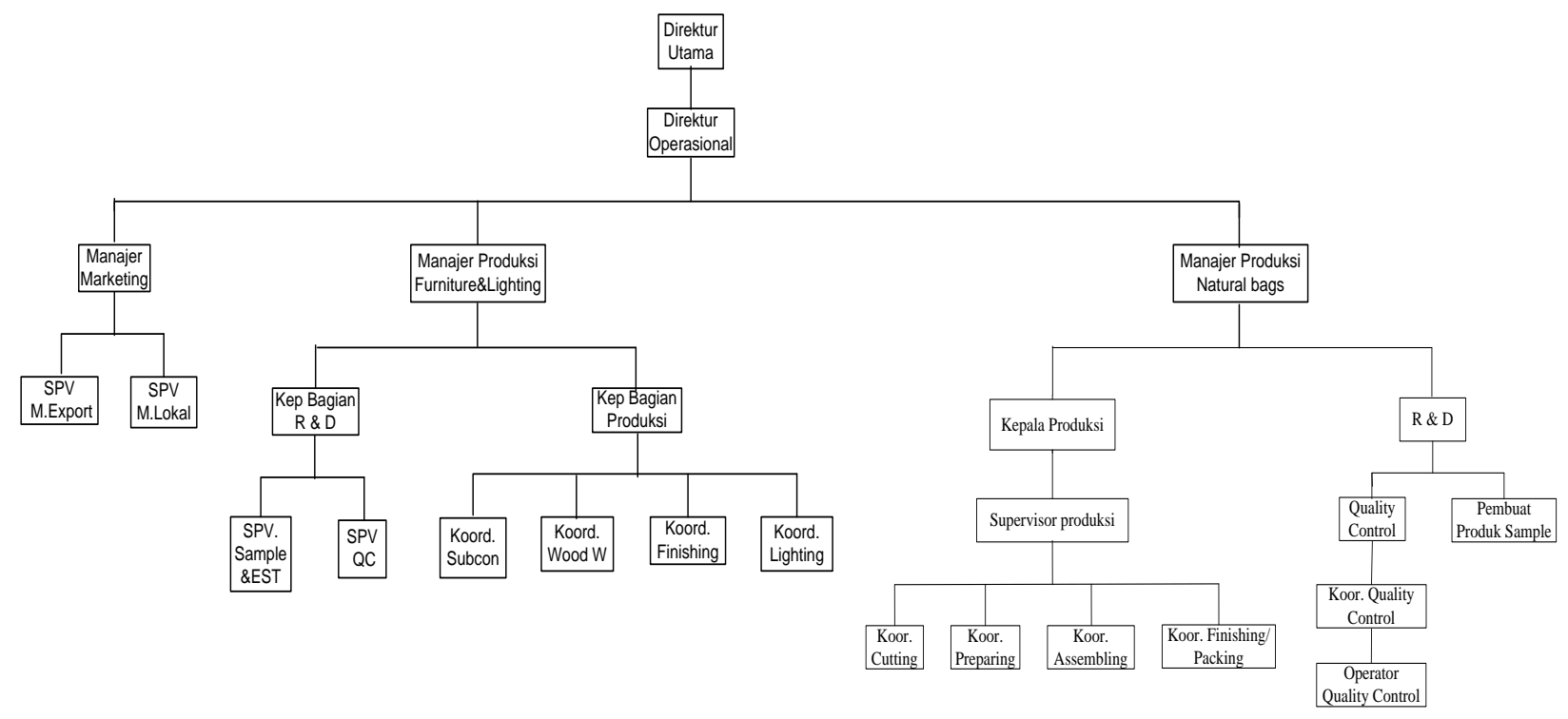

Gambar 1. Struktur organisasi divisi natural bags

Tabel 2. Rekapitulasi data hubungan ketergantungan antar kriteria penilaian oleh bagian produksi

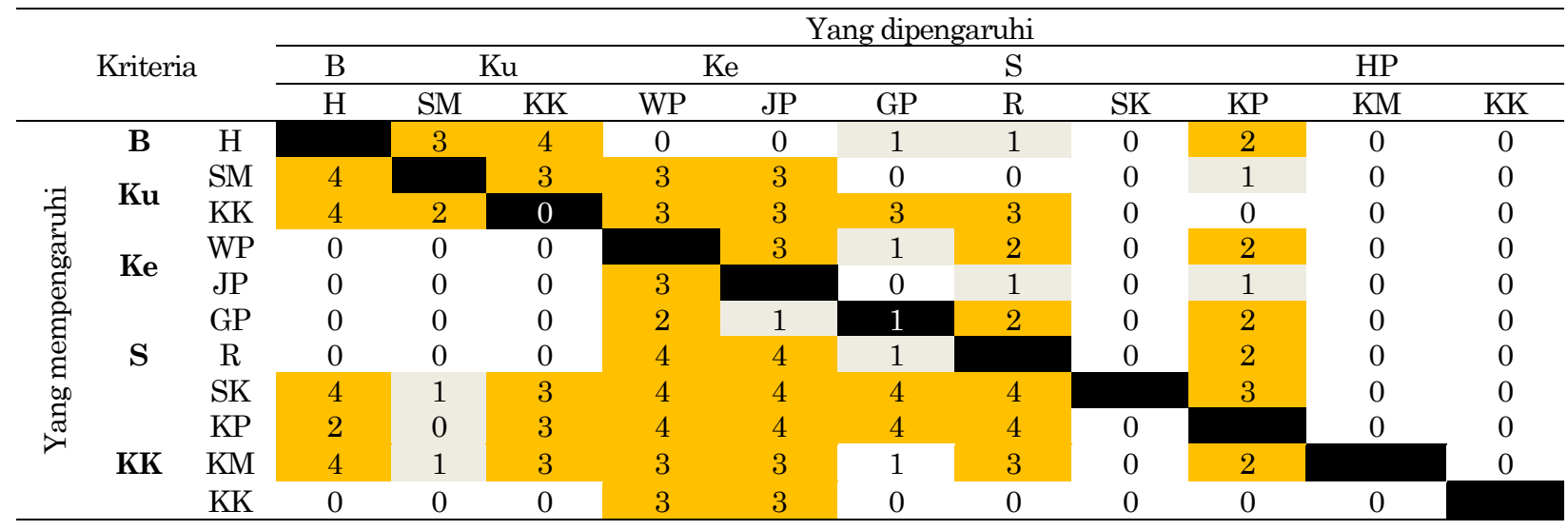

Tabel 3. Rekapitulasi data hubungan ketergantungan antar kriteria penilaian oleh pihak manajemen

\begin{tabular}{|c|c|c|c|c|c|c|c|c|c|c|c|c|c|}
\hline \multirow{3}{*}{\multicolumn{3}{|c|}{ Kriteria }} & \multicolumn{11}{|c|}{ Yang dipengaruhi } \\
\hline & & & \multirow{2}{*}{$\begin{array}{l}\mathrm{B} \\
\mathrm{H}\end{array}$} & \multicolumn{2}{|c|}{$\mathrm{Ku}$} & \multicolumn{2}{|c|}{$\mathrm{Ke}$} & \multicolumn{3}{|c|}{$\mathrm{S}$} & \multicolumn{3}{|c|}{$\mathrm{HP}$} \\
\hline & & & & SM & KK & $\mathrm{WP}$ & $\mathrm{JP}$ & GP & $\mathrm{R}$ & SK & $\mathrm{KP}$ & $\mathrm{KM}$ & KK \\
\hline \multirow{11}{*}{ 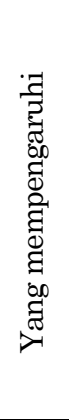 } & B & $\mathrm{H}$ & -6 & $\sqrt{ }$ & $\sqrt{ }$ & $\sqrt{ }$ & $\mathrm{X}$ & $\sqrt{ }$ & $\mathbf{x}$ & $\mathrm{X}$ & $\sqrt{ }$ & $\mathrm{X}$ & $\sqrt{ }$ \\
\hline & & $\mathrm{SM}$ & $\sqrt{ }$ & & $\sqrt{ }$ & $\sqrt{ }$ & $\mathbf{X}$ & $\sqrt{ }$ & $\mathbf{x}$ & $\mathbf{X}$ & $\sqrt{ }$ & $\mathbf{X}$ & $\mathbf{X}$ \\
\hline & Ku & KK & $\sqrt{ }$ & $\sqrt{ }$ & & $\sqrt{ }$ & $\mathbf{X}$ & $\sqrt{ }$ & $\mathbf{x}$ & $\mathrm{X}$ & $\sqrt{ }$ & $\mathrm{X}$ & $\mathbf{X}$ \\
\hline & & WP & $\sqrt{ }$ & $\mathbf{x}$ & $\sqrt{ }$ & & $\sqrt{ }$ & $\sqrt{ }$ & $\mathbf{x}$ & $\sqrt{ }$ & $\sqrt{ }$ & $\mathrm{X}$ & $\mathrm{X}$ \\
\hline & $\mathbf{K e}$ & JP & $\mathbf{x}$ & $\mathbf{x}$ & $\sqrt{ }$ & $\sqrt{ }$ & & $\mathbf{X}$ & $\mathbf{x}$ & $\sqrt{ }$ & $\sqrt{ }$ & $\mathrm{X}$ & $\mathrm{X}$ \\
\hline & & GP & $\sqrt{ }$ & $\sqrt{ }$ & $\sqrt{ }$ & $\sqrt{ }$ & $\sqrt{ }$ & & $\sqrt{ }$ & V & $\sqrt{ }$ & $\mathrm{X}$ & $\mathbf{X}$ \\
\hline & $\mathbf{S}$ & $\mathrm{R}$ & $\sqrt{ }$ & $\sqrt{ }$ & $\sqrt{ }$ & $\sqrt{ }$ & $\sqrt{ }$ & $\sqrt{ }$ & 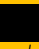 & $\mathbf{X}$ & $\sqrt{ }$ & $\mathbf{X}$ & $\mathbf{X}$ \\
\hline & & SK & $\mathbf{x}$ & $\mathbf{x}$ & $\mathbf{x}$ & $\sqrt{ }$ & X & $\sqrt{ }$ & $\sqrt{ }$ & & $\sqrt{ }$ & $\mathbf{X}$ & $\mathbf{X}$ \\
\hline & & KP & $\sqrt{ }$ & $\mathbf{x}$ & $\sqrt{ }$ & $\sqrt{ }$ & $\sqrt{ }$ & $\sqrt{ }$ & $\sqrt{ }$ & $\sqrt{ }$ & 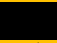 & $\sqrt{ }$ & $\sqrt{ }$ \\
\hline & KK & $\mathrm{KM}$ & $\mathbf{x}$ & $\mathbf{x}$ & $\sqrt{ }$ & $\sqrt{ }$ & $\sqrt{ }$ & $\sqrt{ }$ & $\sqrt{ }$ & $\sqrt{ }$ & $\sqrt{ }$ & & $\sqrt{ }$ \\
\hline & & KK & $\sqrt{ }$ & $\mathbf{x}$ & $\mathbf{x}$ & $\mathbf{x}$ & $\mathrm{X}$ & $\mathbf{X}$ & $\mathbf{x}$ & $\mathbf{X}$ & $\sqrt{ }$ & $\mathrm{X}$ & \\
\hline
\end{tabular}




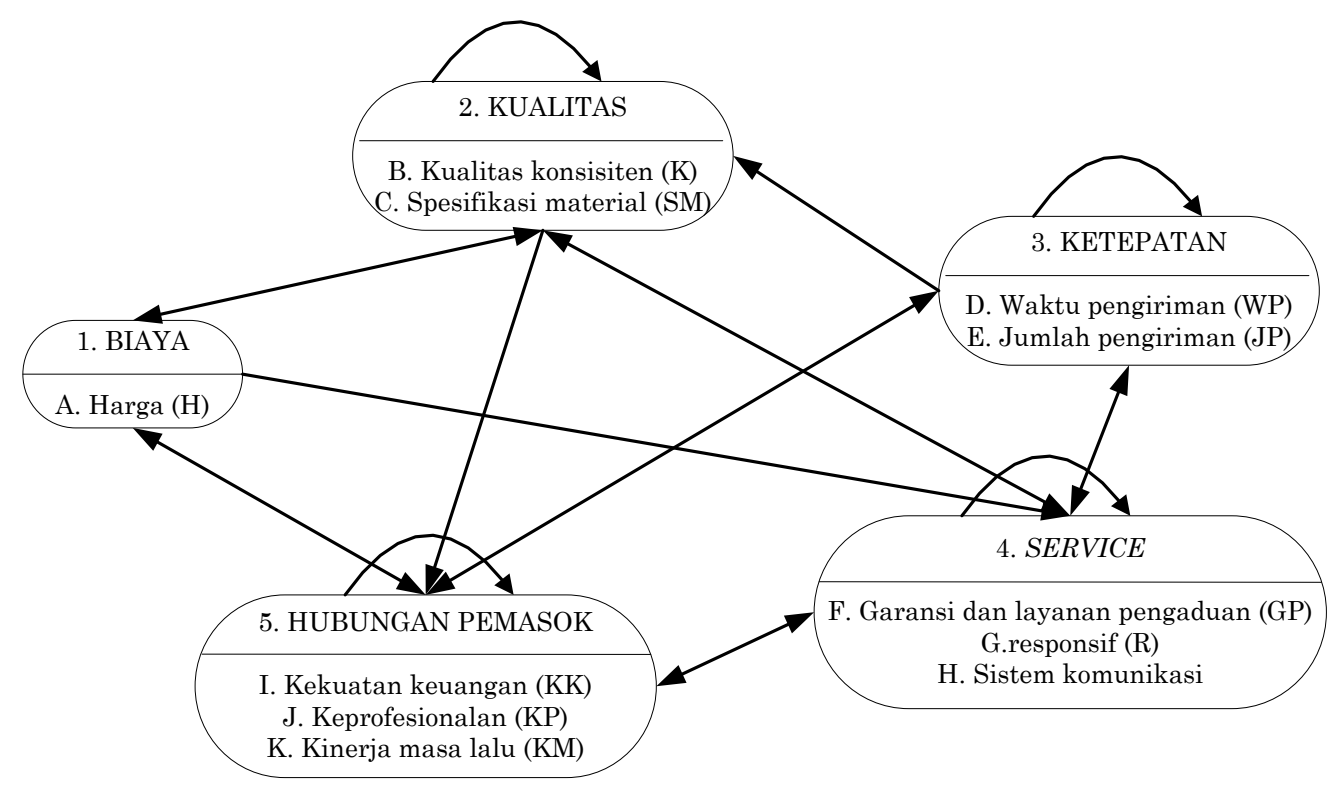

Gambar 2. Model penentuan kriteria yang berpengaruh dalam pemilihan pemasok menggunakan Analytical Network Process (ANP)

\section{Hasil dan Pembahasan}

\section{Pengumpulan Data}

Dalam proses ANP, dilakukan penyebaran kuesioner untuk menentukan hubungan ketergantungan antar kriteria yang dinilai oleh responden dari pihak produksi dan pihak manajemen. Hasil kuesioner digunakan untuk menggambarkan hubungan antar kriteria sebagaimana disajikan dalam Tabel 2 dan Tabel 3.

Pada Tabel 2 penilaian dilakukan oleh pihak produksi dimana terdapat 4 jumlah responden yaitu dari bagian research and development, quality control, kepala produksi natural bags, dan kepala bagian divisi natural bags, sehingga jika dalam suatu sel, jumlah responden yang memilih (Vij) lebih dari atau sama dengan $\mathrm{Q}(\mathrm{N} / 2=2)$, maka disimpulkan ada hubungan saling ketergantungan antar kriteria (Wibowo [18]). Sebagai contoh pada sel H$\mathrm{KK}$, nilai $\mathrm{Vij}=4$ berarti ada pengaruh dari $(\mathrm{H})$ terhadap (KK).

Pada Tabel 3 penilaian dilakukan oleh pihak manajemen dimana hanya terdapat satu responden yaitu pihak manajemen. Simbol centang $(\sqrt{ })$ menunjukkan bahwa kedua kriteria mempunyai hubungan mempengaruhi sedangkan simbol silang $(\mathrm{X})$ menunjukkan tidak ada hubungan antara kedua kriteria.

\section{Pengolahan Data}

Hubungan ketergantungan antar kriteria digunakan untuk membuat model jaringan (network) antar kriteria sebagai dasar pemilihan pemasok yang tersaji pada Gambar 2. Gambar tersebut menunjukkan keterkaitan kriteria dalam kluster (inner dependence) dan antar kluster (outer dependence). Keterkaitan antar kriteria tersebut digunakan untuk menyusun kuesioner perbandingan berpasangan antar kriteria dan kluster. Hasil perbandingan berpasangan yang telah diuji dengan rataan geometrik digunakan sebagai masukan ke perangkat lunak Super Decisions.

Keluaran dari perangkat lunak Super Decisions yang berupa kolom limiting digunakan untuk menunjukkan bobot global. Bobot lokal kriteria diperoleh dari hasil prioritas akhir pada kolom normalized by cluster. Dari bobot global ini dapat dihitung bobot lokal kluster dengan cara membagi nilai bobot global dengan bobot lokal kriteria. Hasil perhitungan bobot lokal dan bobot global dapat dilihat pada Tabel 4 untuk penilaian bagian produksi dan Tabel 6 untuk penilaian pihak manajemen.

Bobot kriteria pemilihan pemasok pada dasarnya menunjukkan urutan prioritas atau pengaruh kriteria dalam pemilihan pemasok. Semakin besar bobot suatu kriteria maka semakin tinggi prioritas atau semakin besar pengaruh kriteria tersebut dalam proses pemilihan pemasok, dan sebaliknya.

Strategi rantai pasok digunakan sebagai perencanaan dan pengendalian aliran material atau informasi dan aktivitas logistik secara internal dan eksternal. Proses pengadaan, operasi, dan kegiatan lain harus terintegrasi dalam rantai pasok dan strategi yang diterapkan mampu mendukung sistem mana- 
jemen untuk membantu perkembangan hubungan jangka panjang, membangun komitmen, kepercayaan, komunikasi, kerjasama antara perusahaan dan pemasok (Lang et al. [12]).

Penting bagi perusahaan untuk melakukan pemilihan pemasok secara efektif agar dapat mengurangi biaya produksi secara signifikan. Seperti halnya Lunar Cipta Kreasi, dalam melakukan pemilihan pemasok juga berorientasi pada pentingnya kelangsungan hubungan dan konsistensi menjaga produk- tivitas dan mutu produknya. Dalam hal ini perusahaan juga harus bekerja sama dengan pemasok agar mampu meningkatkan kepuasaan bagi pelanggan (Lin [13]). Dapat dikatakan pemilihan pemasok merupakan keputusan strategis bagi perusahaan untuk terus mengembangkan usahanya sebagaimana bagi Lunar Cipta Kreasi. Dalam hal ini perlu bagi Lunar Cipta Kreasi untuk menyusun strategi rantai pasoknya dengan menekankan kepada kriteria kinerja, kualitas, ketepatan pengiriman dan sistem komunikasi yang digunakan.

Tabel 4. Hasil perhitungan bobot lokal dan bobot global penilaian pihak produksi

\begin{tabular}{|c|c|c|c|c|}
\hline Kluster & Bobot lokal & Kriteria & Bobot lokal & Bobot global \\
\hline Biaya & 0,20 & Harga & 1,00 & 0,20 \\
\hline \multirow[t]{2}{*}{ Kualitas } & 0,10 & Spesifikasi material & 0,52 & 0,05 \\
\hline & & Kualitas konsisten & 0,48 & 0,05 \\
\hline \multirow[t]{2}{*}{ Ketepatan } & 0,04 & Waktu pengiriman & 0,78 & 0,03 \\
\hline & & Jumlah pengiriman & 0,22 & 0,01 \\
\hline \multirow[t]{3}{*}{ Service } & 0,18 & Garansi dan layanan pengaduan & 0,10 & 0,02 \\
\hline & & Responsif & 0,09 & 0,02 \\
\hline & & Sistem komunikasi & 0,81 & 0,15 \\
\hline \multirow{3}{*}{$\begin{array}{l}\text { Hubungan } \\
\text { pemasok }\end{array}$} & 0,48 & Kekuatan keuangan pemasok & 0,06 & 0,03 \\
\hline & & Keprofesionalan pemasok & 0,21 & 0,10 \\
\hline & & Kinerja masa lalu pemasok & 0,73 & 0,35 \\
\hline Total & & & & 1 \\
\hline
\end{tabular}

Tabel 5. Peringkat kriteria dalam pemilihan pemasok penilaian pihak produksi

\begin{tabular}{lcc}
\hline \multicolumn{1}{c}{ Kriteria } & Bobot & Peringkat \\
\hline Kinerja masa lalu & 0,35 & 1 \\
Harga & 0,20 & 2 \\
Sistem komunikasi & 0,15 & 3 \\
Keprofesionalan pemasok & 0,10 & 4 \\
Kualitas konsisten & 0,05 & 5 \\
Spesifikasi material & 0,05 & 6 \\
Waktu pengiriman & 0,03 & 7 \\
Kekuatan keuangan & 0,03 & 8 \\
Garansi dan layanan pengaduan & 0,02 & 9 \\
Responsif & 0,02 & 10 \\
Jumlah pengiriman & 0,01 & 11 \\
\hline
\end{tabular}

Tabel 6. Hasil perhitungan bobot lokal dan bobot global penilian pihak manajemen

\begin{tabular}{|c|c|c|c|c|}
\hline Kluster & Bobot lokal & Kriteria & Bobot lokal & Bobot global \\
\hline Biaya & 0,14 & Harga & 1,00 & 0,14 \\
\hline \multirow[t]{2}{*}{ Kualitas } & 0,26 & Spesifikasi material & 0,58 & 0,11 \\
\hline & & Kualitas konsisten & 0,42 & 0,15 \\
\hline \multirow[t]{2}{*}{ Ketepatan } & 0,35 & Waktu pengiriman & 0,68 & 0,24 \\
\hline & & Jumlah pengiriman & 0,32 & 0,11 \\
\hline \multirow[t]{3}{*}{ Service } & 0,12 & Garansi dan layanan pengaduan & 0,48 & 0,06 \\
\hline & & Responsive & 0,42 & 0,05 \\
\hline & & Sistem komunikasi & 0,11 & 0,01 \\
\hline \multirow[t]{3}{*}{ Hubungan pemasok } & 0,12 & Keprofesionalan & 0,07 & 0,10 \\
\hline & & Kinerja masa lalu & 0,81 & 0,02 \\
\hline & & Kekuatan keuangan & 0,12 & 0,01 \\
\hline Total & & & & 1 \\
\hline
\end{tabular}


Tabel 7. Peringkat kriteria dalam pemilihan pemasok penilaian pihak manajemen

\begin{tabular}{lcc}
\hline \multicolumn{1}{c}{ Kriteria } & Bobot & Peringkat \\
\hline Waktu pengiriman & 0,24 & 1 \\
Kualitas konsisten & 0,15 & 2 \\
Harga & 0,14 & 3 \\
Jumlah pengiriman & 0,11 & 4 \\
Spesifikasi material & 0,11 & 5 \\
Keprofesionalan pemasok & 0,10 & 6 \\
Garansi dan layanan pengaduan & 0,06 & 7 \\
Responsif & 0,05 & 8 \\
Kinerja masa lalu & 0,02 & 9 \\
Kekuatan keuangan & 0,01 & 10 \\
Sistem komunikasi & 0,01 & 11 \\
\hline
\end{tabular}

Berdasarkan hasil observasi diketahui bahwa pemilihan pemasok oleh Lunar Cipta Kreasi masih mengacu pada aspek kualitas sesuai dengan spesifikasi. Pengambilan keputusan seperti ini menimbulkan masalah dalam hal ketidaktepatan waktu pengiriman, spesifikasi bahan baku tidak sesuai dengan kesepakatan, ketidakprofesionalan dalam menjalankan kerjasama dan lain-lain. Oleh karena itu dilakukan penelitian ini untuk mengurangi kesalahan dalam pemilihan pemasok yang nantinya akan berakibat pada proses produksi perusahaan.

Menurut pihak produksi Lunar Cipta Kreasi, kriteria-kriteria yang dianggap penting dalam pemilihan pemasok adalah kinerja masa lalu, harga, sistem komunikasi, dan keprofesionalan pemasok. Kriteria-kriteria tersebut menyumbang bobot yang paling besar (pada Tabel 5). Menurut pihak manajemen kriteria yang dianggap penting adalah waktu pengiriman, kualitas konsisten, harga, dan jumlah pengiriman (pada Tabel 7).

Kondisi ini menunjukkan bahwa terjadi perbedaan sudut pandang dalam kriteria yang digunakan untuk pemilihan pemasok. Spesifikasi material yang awalnya dianggap penting bagi perusahaan ternyata memberikan bobot terkecil. Hal ini menunjukkan bahwa kriteria yang digunakan selama ini sudah tidak relevan lagi. Kriteria untuk pemilihan pemasok pun perlu disesuaikan lagi.

Berdasarkan Tabel 6 dan Tabel 7 juga menunjukkan bahwa kriteria harga masih menjadi prioritas dalam pemilihan pemasok baik menurut pihak produksi maupun pihak manajemen. Namun pihak produksi lebih menekankan kriteria kinerja masa lalu sebagai kriteria terpenting. Kinerja masa lalu ini terkait dengan catatan penting hubungan yang terjadi antara pemasok dan perusahaan. Pihak manajemen menganggap waktu pengiriman adalah kriteria terpenting dalam pemilihan pemasok.

Dalam mengkaji dua sudut pandang yang berbeda tersebut diperlukan pendekatan dari sisi kepenting- an perusahaan untuk jangka pendek maupun jangka panjangnya. Pemahaman ini dapat dijelaskan melalui jaringan pada Gambar 2. Sebagimana terlihat bahwa kluster hubungan pemasok dipengaruhi oleh kluster kualitas. Artinya bagi bagian produksi sesaat setelah menentukan macam atau tingkat kualitas yang diinginkan (sesuai spesifikasi) maka tentunya akan menentukan hubungan yang dapat berlanjut dengan referensi salah satunya ialah kinerja masa lalu. Kluster hubungan pemasok juga berpengaruh terhadap kluster ketepatan dengan kriteria waktu dan jumlah atau kuantitas yang dikirim. Nampak bahwa asumsi ini memiliki latar belakang akan kepentingan bagian produksi dalan jangka pendek agar dapat memenuhi target order.

Di sisi lain pihak manajemen memandang waktu pengiriman sebagai prioritas pertama. Hal ini terkait dengan pemahaman bahwa dengan pengiriman yang tepat waktu maka akan menjamin kelancaran lintasan produksi sehingga jadwal pengiriman dapat segera ditetapkan. Dalam hal ini jelas bahwa pihak manajemen lebih mengutamakan kepentingan jangka panjang yaitu agar diperoleh kepercayaan dan loyalitas dari pelanggan.

Dua cara pandang yang berbeda tersebut memerlukan perlakuan yang seimbang sehingga dapat ditekankan arti penting penyelarasan persepsi agar perencanaan rantai pasok Lunar Cipta Kreasi dapat mempertimbangkan aspek kelancaran lintasan produksi dan tercapainya kepuasan pelanggan atas dasar ketepatan waktu pengirimannya. Hal ini dapat diatasi dengan melibatkan pemasok dalam akses pasar yang dilayani oleh Lunar Cipta Kreasi. Harapan bahwa aktivitas rantai pasoknya dapat memberikan keberhasilan untuk memenuhi dua prioritas yang berbeda tersebut dapat tercapai.

Hasil penentuan prioritas kriteria ini dapat digunakan bagi Lunar Cipta Kreasi sebagai dasar pemilihan pemasok. Pemilihan pemasok yang sesuai dengan kriteria yang diinginkan oleh perusahaan akan membuka peluang kemitraan jangka panjang. Kemitraan jangka panjang dapat menjaga komitmen antar kedua belah pihak sehingga dapat menjamin aliran material dengan spesifikasi material yang sesuai baik dalam tingkat kualitas, waktu dan jumlah pengirimannya. Risiko pun dapat diminimalisir sehingga memperlancar arus produksi dan mengurangi biaya produksi perusahaan.

\section{Simpulan}

Penting bagi perusahaan yang menjadi obyek penelitian di sini untuk melakukan evaluasi terhadap kriteria yang berpengaruh dalam pemilihan 
pemasok. Dalam hal ini perlu penyelasaran cara pandang terhadap kriteria dimaksud dari dua strata jabatan yang berbeda yang juga mewakili tingkat kepentingan yang berbeda. Kriteria yang selama ini digunakan dapat disimpulkan sudah tidak relevan lagi karena kriteria tersebut tidak memberikan kehandalan dalam kontinuitasnya. Oleh karena itu, pemilihan pemasok berdasarkan kriteria yang tepat yang sesuai dengan kebutuhan dalam kepentingan jangka waktunya, serta efektif ialah akan berpengaruh secara gradual dalam mengurangi biaya produksi, meningkatkan produktifitas dan kepuasan konsumen.

\section{Daftar Pustaka}

1. Amid, A., Ghodsypour, S. H., and O'Brien, C. A., Weighted Max-Min Model for Fuzzy MultiObjective Supplier Selection in a Supply Chain, International Journal Production Economics, 131, 2011, pp. 139-145.

2. Bayazit, O., Use of Analytical Network Process in Vendor Selection Decisions, An International Journal, 13(5), 2006, pp. 566-579.

3. Cebi, F., and Bayraktar, D., An Integrated Approach for Supplier Selection, Journal of Logistics Information Management, 16(6), 2003, pp. 395-400.

4. Celebi, D., Bayraktar, D., and Bingol, L., Analytical Network Process for Logistics Managemen: A Case Study in Small Electronic Appliances Manufakturer, An International Journal Computers and Industrial Engineering, 58, 2010, pp. 432-441.

5. Chen, Y. J., Structured Methodology for Supplier Selection and Evaluation in a Supply Chain, An International Journal Information Sciences, 181, 2011, pp. 1651-1670.

6. Chung, S. H., Lee, A. H., and Pearn, W. L., Analytic Network Process (ANP) Approach for Product Mix Planning in Semiconductor Fabricator, Journal of Production Economics, 96, 2005, pp. 15-36.

7. Dewayana, S. T., dan Budi, A., Pemilihan Pemasok Cooper Rod Menggunakan Metode ANP., Jurnal Jurusan Teknik Industri Universitas Diponegoro, IV(3), 2009, pp 212-217.

8. Gencer, C., and Gurpinar, D., Analytic Network Process in Supplier Selection: A Case Study in an Electronic Firm, Journal of Applied Mathematical Modeling, 31, 2007, pp. 2475-2486.
9. Ghodsypour, S. H., and O'Brien C., The Total Cost of Logistics in Supplier Selection, under Conditions of Multiple Sourching, Multiple Criteria and Capacity Constraints, International Journal of Production Economics, 73, 2001, pp. 15-27.

10. Hapsari, P. K., dan Suparno, Integrasi Fuzzy Analytic Network Process dan Goal Programming dalam Pemilihan Supplier dan Alokasi Order, Skripsi, Jurusan Teknik Industri, Institut Teknologi Sepuluh November, Surabaya, 2010.

11. Jharkharia, S., and Shankar, R., Selection of Logistics Service Provider: An Analytical Network Process Approach. The International Journal of Management Science, 35, 2005, pp. 274289.

12. Lang, T. M., Chiang, J. H., and Lan, L. W., Selection of Optimal Supplier in Supply Chain Management Strategy with Analytic Network Process and Choquet Integral, An International Journal Computers and Industrial Engineering 57, 2009. pp. 330-340.

13. Lin, C. T., Chen, C. B., and Ting, Y. C., An ERP Model for Supplier Selection in Electronics Industry, An International Journal Expert Systems with Applications 38, 2011, pp. 1760-1765.

14. Ng, Wang. L., An Efficient and Simple Model for Multiple Criteria Supplier Selection Problem, European Journal of Operational Research, 186, 2008, pp. 1059-1067.

15. Sarkis, J., and Talluri, S., A Model for Stategic Supplier Selection, Journal of Supply Chain Management, 38(1), 2002, pp. 18-23.

16. Tam, M. C. Y., and Tummala, V. M. R., An Application of The AHP in Vendor Selection of a Telecomunication System, International Journal of Management Science, 29, 2001, pp. 171-182.

17. Wang, G., Hang, S. H., and Dismukes, J. P., Product-driven Supply Chain Selection Using Intergrated Multi-criteria Decision Making Methodology, International Journal of Production Economics, 91, 2004, pp. 1-15.

18. Wibowo, M. R., Perancangan Model Pemilihan Mitra Kerja dalam Penyediaan Rig Darat dengan Metode Analytical Network Process (ANP), Tesis, Fakultas Teknik, Universitas Indonesia, 2010.

19. Yoserizal, Y., and Singgih, M. L., Integrasi Metode Dematel (Decision Making Trial and Evaluation Laboratory) dan ANP (Analytical Network Process) dalam Evaluasi Kinerja Supplier di PT. XYZ, Prosiding Seminar Nasional Manajemen Teknologi XV, ITS, Surabaya, 2012. 